\title{
AO ENCONTRO DE HEIDEGGER: a noção de Ser-no-Mundo
}

FINDING HEIDEGGER: what is Being-in-the-World

Jeannette Antonios Maman ${ }^{1}$

Resumo:

Trata-se de esclarecer a noção de Ser-no-Mundo para melhor compreensão do fenômeno jurídico na linha de pesquisa da fenomenologia de Martin Heidegger.

Palavras-chave: Fenomenologia. Filosofia do ser. Ser-no-mundo.

Abstract:

This paper is a initiation into Phenomenological Reserch of Martin Heidegger and the study wich is Being-in-the-World for understanding law phenomenon.

Keywords: Law phenomenom. Philosophy of the being. Being-in-the-world.

1. Abrindo caminhos

A História de Filosofia, de Nicola Abbagnano, inclui, equivocadamente, entre os existencialistas, o pensador Martin Heidegger.

$\mathrm{O}$ próprio Heidegger não se admitia como existencialista. Muito corretamente, devemos considerá-lo um "refundador" da filosofia do ser, que rompe com a metafísica tradicional, de Aristóteles a Kant, e indicar - para investigação de Ontologia fundamental - não a filosofia do ser que busca os fundamentos, mas o pensar sobre os entes - naquilo que é mais importante. Esta é a tarefa do Dasein (ser-o-aí, ser-humano-existenteem-situação-com-o-outro, para a morte). A última das possibilidades é, paradoxalmente, uma impossibilidade - a morte.

O caminho investigativo da filosofia do ser heideggeriana é fenomenológico.

$\mathrm{O}$ fenômeno se estende para um desvelar de sua interiosidade. Este encontro não se dá se não há disposição para buscá-lo, fora-de-si pelo Dasein.

Assim responderemos às inquietações filosóficas do por que as coisas são assim ou por que não são de outro modo.

Esta é a via quando buscamos a compreensão do fenômeno jurídico.

1 Professora Doutora do Departamento de Filosofia do Direito da Faculdade de Direito da Universidade de São Paulo. 
A fenomenologia não é um método. É a via investigativa da filosofia do ser:

\begin{abstract}
A fenomenologia é a via de acesso e o modo de verificação para se determinar o que deve constituir tema da ontologia. A ontologia só é possível como fenomenologia (Heidegger, Ser e Tempo, em tradução de Cavalcante, 1988).
\end{abstract}

De Husserl, restou à fenomenologia heideggeriana, que tomaria outros rumos, a noção de mundo vivido (experiência de vida, experienciação do mundo) e a consciência-fora-de-si: a intencionalidade da consciência resulta do fato de ser sempre consciência de alguma coisa, na compreensão dos modos como as coisas são, como os objetos se apresentam (daí a "intuição” husserliana).

No fenômeno da existência de Dasein há duas estruturas constitutivas: a existencial (que compõe o cotidiano, o estar-junto, sem a consciência do sentido deste existir, sem o exercício da capacidade de julgar, como diria Hannah Arendt) e a existenciária, onde se dá o mundo autêntico da existência-em-comum, que não se resume ao mundo da ocupação, dos ofícios técnicos, mas se traduz pelo cuidado que é manifesto na preocupação-com-o-outro.

Rompe-se a corrente da filosofia alemã idealista e romântica. É o adeus à imanência do sujeito e ao subjetivismo do mundo moderno.

Contrapõe-se tal caminho investigativo ao dogmatismo como corrente teórica, já que a situação existencial é aquela do poder-ser, das possibilidades que se abrem, mas que são apenas previsíveis, onde as escolhas estão sujeitas ao imprevisto, ao qual não nos entregamos, como outorga do destino, mas procuramos superá-lo pela condição de seres resolutos.

\title{
2. Terminologia filosófica de Ser e Tempo: Ser-no-Mundo
}

1) A filosofia de Heidegger pede a exegese ontológica do ser-no-mundo, dos elementos constitutivos da totalidade fenomênica de ser-no-mundo.

A compreensão ontológica da mundanidade, ${ }^{2}$ como seres simplesmente dados (seres aqui usados como sinônimo de entes - totalidade dos entes existentes em geral) - Vorhanden: seres à mão mas sobretudo, à vista, e que impõem limite ao exercício da manualidade como possibilidade de desempenho do exercício da mão, exercício histórico definitivo para o uso de artefatos (como a capacidade de pinça do polegar para apreensão

\footnotetext{
2 Mundanidade como cotidiano, o dia a dia das ocupações.
} 
e utilização de ferramentas) no que diz respeito ao Dasein (ser-humano-existente) deve ser compreendida com a condição de não se referir a ele, pois o Dasein não pode ser considerado como coisa.

Seres constituídos pela manualidade e que são os disponíveis como instrumentos, utensílios, artefatos em geral (Zuhanden): estão à mão e podem ou não ser instrumentalizados.

2) Quem é no cotidiano, na mundanidade, o Dasein?

O Dasein é, imediatamente, "tomado" pelo mundo. Envolvido pelo mundo como um ente na totalidade dos entes, em geral. Originariamente, o Dasein é ser-nomundo, situação que faz parte de sua constituição, é elemento estrutural, no sentido de "constituinte", o que está na origem da existência.

Estruturas igualmente originárias são: ser-com e ser-o-aí-com.

O "sujeito" do cotidiano, qualquer um, não se perde, necessariamente, (como determinação natural) no impessoal, reserva-se-lhe o espaço de ser-si-mesmo, ser próprio, ser autêntico.

A descrição imediata do mundo circundante, por exemplo, do trabalhador manual, lança, projeta como resultado: ao trabalho, enquanto utilidade, "fazem frente", coexistem aqueles aos quais se destina a obra do trabalhador. $\mathrm{O}$ artefato tem que ser feito à medida de quem os utilizará. Igualmente, está visível, está entre os entes existentes, o produtor do trabalho (do artefato) que servirá "bem" ou "mal".

Os outros, que fazem frente ao conjunto de utensílios disponíveis (à mão) no mundo, não se referem mentalmente a uma coisa "diante dos olhos", mas estas coisas fazem frente, destacando-se do mundo em que são disponíveis aos outro, mundo desde sempre que também lhes é próprio (es ya siempre también el mio, na tradução de Gaos).

O mundo do Dasein é mundo compartilhado (Mitwelt). O Dasein é Mitdasein e não um eu isolado, onde os "outros" significariam o "resto" além de mim.

O outro não é um Vorhanden disponível no sentido de manipulável, instrumentalizável. Isto é o que dá humanidade ao ser humano existente.

Decorre daí:

a) Não há isolamento do sujeito, no conjunto social:

Foi na escola de Husserl que se desenvolveu o pensamento de Heidegger. Seria demasiado longo investigar todos os elementos que, de Husserl, vêm até Heidegger. Seria necessário falar da idéia de intencionalidade que, segundo Heidegger, só se pode explicar pela idéia de transcendência tal como ele a compreende... Não é menos verdade que a idéia, essencial em Heidegger, de ser-no-mundo vem 
de Husserl. Não há dúvida de que Husserl propôs que se pusesse o mundo entre parêntesis; mas, por outro lado - e é o que, Merleau-Ponty sublinha no prefácio de sua tese $-A$ Fenomenologia da Percepção - faz-nos tomar consciência de que finalmente isso é impossível e que todas as nossas idéias se fundamentam no que podemos chamar de base antepredicativa que é o nosso ser-no-mundo (Wahl, 1962).

O indivíduo não se perde no impessoal, ele se "encontra" no coletivo.

“... fizeram a Heidegger o reparo de ele considerar o indivíduo como isolado, o que não é exato... tal filosofia [a de Heidegger] diz-nos que não há sujeito em face de um objeto, que se deve destruir o conceito clássico de sujeito, fazê-lo estalar" (Wahl, 1962).

b) O indivíduo, no sentido singular, não é um ser que despenca no abismo de sua subjetividade, existe-em-conjunto. É a "fusão social" sartreana - não há espaço para o sujeito isolado.

\section{A investigação do "olhar penetrante"}

Buscar a fundo uma "coisa" (no sentido heideggeriano) pede investigação que faz mover o "olhar" para seu ser e sua verdade, que não é fundamento ou razão, mas o solo onde se enraíza sua existência, no desfundo próprio de existir-no-mundo.

Há diversos modos-de-ser e diversos modos de "visão". Compomos o texto com "olhos fixos" no mundo fenomênico, recurso da via fenomenológica, que não se rendeu ao pequeno mundo da metodologia e da lógica. Se estes instrumentais nos permitem dar clareza à exposição do pensamento e orientar o raciocínio analítico, não significa que seguimos um "método", a não ser que assim consideremos a palavra na sua vertente originária grega - caminho.

A tradução mais divulgada de Ser e Tempo para a língua portuguesa é de Márcia Cavalcante (Editora Vozes).

O esforço despendido nesta obra de fôlego, ainda que sob orientação de um dos mais conhecidos estudiosos de Heidegger, no Brasil - Emmanuel Carneiro Leão, não impede que nos limites de nosso modesto alemão instrumental, mas movidos por um esforço constante para melhor conhecer e pensar a filosofia de Martin Heidegger, e então aproximá-la do fenômeno jurídico, apresentem-se propostas para melhor compreensão.

Quando Cavalcante traduziu Umsicht por circunvisão está correto. Mas, ao traduzir as composições do radical ver (Sicht) com preposições ou partículas conotativas como Rück- Sicht opta por "consideração". Citando: "Assim, Rück-Sicht indica uma 
maneira de ver, que leva em conta a diferença e a importância de tudo com que se lida e se carrega nas costas (Rück). A tradução optou pelo termo consideração" (Cavalcante, 1988, glossário).

Preferimos considerar a expressão como modo de mudar a visão para aceitar as diferenças de situação, que decorrem, não da "tolerância" (como Cavalcante traduz Nach-Sicht) mas do "olhar para", "olhar através de" (Durch-Sicht) que a tradutora atribui o sentido de "transparência".

A situação de ser-no-mundo (das ocupações ou da transcendência) implica olhos atentos ao mundo fenomênico, visão de conjunto, circunvisão que alcança a totalidade dos entes existentes. Esta visão (que já se percebe pelos sentidos) possibilita penetrar a interioridade do fenômeno, desvendando aquilo que se lhe oculta.

Só podemos pensar e conhecer o fenômeno (no nosso caso, o fenômeno jurídico) porque somos desde sempre, lançados, projetados fora de nós. Esta consciência fora de si (no sentido husserliano) é que permite a transcendência, quando então nos superamos a nós mesmos e à situação - limite apresentada pelos acontecimentos que buscamos desvendar, revelar, descobrir.

Dizer "procuro o ek-istir" é dar um passo para fora da caverna, como na alegoria platônica da busca da verdade. Esta atitude vai ampliar, desde a percepção mais simples do fenômeno (visão) a compreensão de mundo, não como uma exigência natural (razão) mas um diálogo com o natural, entendido aqui, não nos limites do pensamento grego (natureza física) mas descrição do mundo fenomênico (totalidade dos entes existentes), a partir deste diálogo (que corresponde como descrição, ao pensamento husserliano). Aqui a linguagem é a palavra e esta é o ser-para-o-outro. É o existir-no-mundo-com-o-outro, sendo no mundo, isto é, envolvido pelo mundo.

São Paulo, dezembro de 2007.

\section{Referências}

HEIDEGGER, Martin. Sein und Zeit. Max Niemeyer Veralg Tübingen, 1993.

. El ser y el tiempo. Traducción de José Gaos. México: Fondo de Cultura Económica, 2002.

. Ser e Tempo. Tradução de Márcia de Sá Cavalcante. Petrópolis: Editora Vozes, 1988.

WAHL, Jean. As filosofias da existência. Lisboa: Coleção Saber, Publicações Europa - América, 1962. 